\title{
The N-of-1 Clinical Trial: A Timely Research Opportunity in Homeopathy
}

\author{
Susanne Ulbrich-Zürni ${ }^{1} \quad$ Michael Teut ${ }^{2}$ Stephanie Roll ${ }^{2}$ Robert T. Mathie ${ }^{3}$
}

1 Swiss Homeopathy Association, Zürich, Switzerland

${ }^{2}$ Institute for Social Medicine, Epidemiology and Health Economics, Charité - Universitätsmedizin Berlin, Berlin, Germany

${ }^{3}$ Homeopathy Research Institute, London, United Kingdom

Address for correspondence Susanne Ulbrich-Zürni, PhD, Swiss Homeopathy Association, Zürich, Switzerland (e-mail: forschung@hvs.ch).

Homeopathy 2018;107:10-18.

\begin{abstract}
Keywords

- complementary and alternative medicine

- homeopathy

- N-of-1 trial

- single-patient trial

- research methods

Background The randomised controlled trial (RCT) is considered the 'gold standard' for establishing treatment efficacy or effectiveness of an intervention, but its data do not infer response in an individual patient. Individualised clinical care, a fundamental principle in complementary and alternative medicine (CAM), including homeopathy, seems well disposed in principle to being researched by single-patient ( $\mathrm{N}$-of- 1 ) study design. Guidelines for reporting N-of- 1 trials have recently been developed.

Objective To overview the current status in the literature of the N-of-1 method and its application in medicine, including CAM. To consider whether the N-of-1 trial design offers an opportunity for novel research in homeopathy.

N-of-1 Trial Design The N-of-1 trial applies the principles of the conventional crossover, blinded, RCT design. The treatment under study and the comparator are repeated in a randomised order, and with suitable washout time, over a defined period. N-of-1 design is constrained for use in chronic stable conditions, and for interventions that have quick onset and cessation of effect, with modest or negligible carryover. Outcome data can be aggregated and interpreted for the individual subject; they can also be pooled with data from several similar $\mathrm{N}$-of- 1 trials, enabling more generalisable conclusions.

The N-of-1 Trial in CAM The typical individualisation of patient care can be accommodated in $\mathrm{N}$-of- 1 study design if the patient and the specific therapeutic intervention are selected within the constraints of the method. Application of the $\mathrm{N}$-of- 1 method in CAM has been advocated but has been mainly limited, in practice, to a small number of studies in herbal and traditional Chinese medicine.

The N-of-1 Trial in Homeopathy Individualised homeopathy can be accommodated for investigation within the same methodological constraints; less in-depth homeopathic approaches to prescribing are also amendable to investigation using the N-of-1 method. No such studies have been published. We identify three main targets in its ready applicability to homeopathy: (1) to optimise clinical care in an individual patient; (2) to investigate whether the outcomes of treatment using homeopathy differ from those of placebo; (3) to aggregate data from a series of $\mathrm{N}$-of- 1 trials to enable broader conclusions about a group of patients or intervention.
\end{abstract}

received

May 3, 2017

accepted

December 11, 2017

published online

January 23, 2018
Copyright @ $\odot 2018$ The Faculty of

Homeopathy
Dol https://doi.org/ 10.1055/s-0037-1621731. ISSN 1475-4916. 
Conclusion The $\mathrm{N}$-of-1 trial design offers important new investigative possibilities in homeopathy and should be explored as a means to optimise individualised health care or investigate effectiveness of the homeopathic intervention compared with placebo in individual subjects.

\section{Introduction}

The nature of research evidence in homeopathy is a matter of ongoing scientific debate. Five systematic reviews have examined the randomised controlled trial (RCT) research literature for all forms of homeopathy across all medical conditions that have been the subject of such research. ${ }^{1-5}$ Four of these systematic reviews reached the conclusion that the homeopathic intervention probably differs from placebo, ${ }^{1-4}$ while the systematic review by Shang et $\mathrm{al}^{5}$ concluded that homeopathy has no effect beyond that of placebo. The reasons for these different results are diverse. However, there is one common conclusion within the homeopathy community: new high-quality research is necessary to enable more decisive interpretation of the RCT evidence. But what comprises 'high-quality research' in homeopathy?

RCTs are properly deemed the 'gold standard' for establishing treatment efficacy or effectiveness for a given intervention. However, no conventional RCT can attempt to inform about that intervention's effect in a particular individual-within the trial itself or in the relevant general population. By contrast, the 'N-of-1' trial design is based on single-case investigation, applying the key principles of the RCT: it is a study conducted in a single patient to whom two or more different treatment options are repeatedly and consecutively applied in a randomised order over time. ${ }^{6-10}$ In appropriate cases, such as when it is unclear which of two or more treatment options might optimally benefit an individual patient or group of similar patients, the N-of- 1 trial may be a valid option in finding the best available treatment.

The term ' $\mathrm{N}$-of- 1 trial' is used in the fields of medicine and the behavioural sciences, but refers to different concepts within each. In the behavioural sciences, the term is often used to refer to any one of several different single-case experimental designs. ${ }^{11,12}$ In medicine, 'N-of-1' typically refers to a prospective multiple-crossover investigation performed in a single individual, using repeated cycles of treatment(s), where one period (typically labelled ' $A$ ') is the treatment being studied and the other period (typically labelled ' $\mathrm{B}$ ') is the control (e.g. standard care, alternative treatment, placebo, or no intervention). ${ }^{6,9,13}$ This latter design may incorporate key elements of a conventional RCT to reduce bias, e.g. randomisation, allocation concealment, and blinding; ${ }^{14}$ its internal validity is therefore high.

$\mathrm{N}$-of- 1 trials have a long history in psychology and education. Over the past 40 years, they have been used in different fields of clinical medicine, ${ }^{10}$ in which a peak of relevant activity took place in the mid-1980s, when Guyatt et al adopted the $\mathrm{N}$-of- 1 trial design in the modern clinical setting. ${ }^{8,15,16}$ Despite some continuing enthusiasm in the 1990s, however, few academic centres conducted N-of-1 trials. ${ }^{17}$ Yet such trials have the potential to play an important role for evidence-based patient-centred care in individualised medicine. ${ }^{17,18}$ A series of $\mathrm{N}$-of- 1 trials can also be performed and has been found to be a useful approach, including the use of appropriate meta-analysis of data-see below.

A more recent revival of interest can be identified, with several recommendations and guidelines for implementation published since 2014.9,19-21 Several systematic reviews $^{22-25}$ and a set of meta-analyses ${ }^{23}$ on the topic have also been conducted. Punja et al analysed a wide range of conditions using N-of-1 methods, including diseases of the nervous system, digestive system, respiratory system, musculoskeletal and connective tissue, and mental and behavioural disorders. ${ }^{23} \mathrm{Li}$ et al examined 112 N-of- 1 trials, involving 2,278 patients, published between 1985 and 2013; ${ }^{25}$ most trials assessed pharmacology and therapeutics or behaviour. The authors concluded that the quality of reporting of published $\mathrm{N}$-of- 1 trials is variable and needs improvement. The 2015 publication of reporting guidelines by the CONSORT Extension for Reporting $N$-of- 1 Trials $(C E N T)^{9,21}$ should elicit improved quality in the future. The CONSORT group acknowledged the usefulness of N-of- 1 trials 'for situations that cannot always accommodate large scale trials' and thus advocated a specific $\mathrm{N}$-of- 1 extension to the regular CONSORT statement. ${ }^{9}$ Nikles argues that $\mathrm{N}$-of- 1 trials are slowly gaining in importance, commenting that N-of-1 trials have recently been published in several different clinical areas, including chronic pain, paediatrics, palliative care, rare diseases, patient-centred care, behavioural sciences, genomics, as well as in complementary and alternative medicine (CAM). ${ }^{26}$

In this article, we first position N-of- 1 trials within the standard hierarchy of research evidence. We then describe methodological considerations for N-of-1 trials in general, giving an overview of the current status in the literature of $\mathrm{N}$ of- 1 methods and their use in CAM. Finally, we discuss the possibilities for the contribution of $\mathrm{N}$-of- 1 trials in research on homeopathy.

\section{The N-of-1 Trial in the Hierarchy of Evidence}

The RCT is generally regarded as the standard method for assessing treatment efficacy (explanatory RCTs) or comparative effectiveness (pragmatic RCTs) as it is intrinsically capable of minimising bias. ${ }^{27-30}$ The advantage of an explanatory design (especially if performed double-blinded) is its high internal validity. Pragmatic RCTs, on the other hand, are 
conducted with the purpose of informing about decisions made in routine everyday practice (i.e. they have higher external validity). When an RCT shows a positive finding, it may be wrongly assumed that all participants benefit by a similar amount, when in reality it is unlikely that every patient does so. The mean treatment effect yielded by an RCT masks what may be important heterogeneity amongst its participants, and precludes a ready knowledge of individual response.

The N-of-1 trial features rarely in standard descriptions of evidence hierarchy. Guyatt et al, ${ }^{31}$ however, have placed N-of-1 trials at the top of the evidence hierarchy for making decisions about treatment benefits and harms, especially in their application to the individual patient. Indeed, the $\mathrm{N}-\mathrm{of}-1$ trial may be viewed as more than merely filling the gap between individual case reporting and the conventional RCT. A suitably designed $\mathrm{N}$-of-1 trial may feasibly optimise both internal and external validity: a risk-of-bias scale has been devised specifically to assess each of those attributes in context. ${ }^{12}$

\section{Practical Issues of $\mathbf{N}$-of-1 Trials}

\section{General Considerations}

As is the case for crossover designs in general, the N-of- 1 trial is usually recommended for chronic stable conditions, and for interventions with a relatively quick onset and cessation of effect, with modest or negligible carryover or cumulative effects. ${ }^{6,8,9}$

Because it is based importantly on repeated return of symptoms, the use of $\mathrm{N}$-of- 1 design is considered especially appropriate in chronic diseases where the intervention palliates the symptoms rather than cures an underlying pathology. It is also recommended in therapy areas that are controversial ${ }^{32}$ or when there is great disparity among the effects of established therapies. N-of- 1 trials are useful for episodic illnesses (e.g. migraine), as long as the frequency of episodes is fairly regular. ${ }^{33} \mathrm{~N}$-of- 1 trials are not suitable for investigating rapidly progressive conditions (e.g. swift continuous improvement or sudden severe clinical outcomes such as stroke or death). ${ }^{6}$ The number and length of the crossover period(s) are determined by the nature of the intervention and the outcome, as well as by the statistical power associated with the number of observations within each period. ${ }^{18}$ Just as in conventional trials and many other clinical studies, a measurement period may be included before the start of the interventions to record the patient's baseline values of relevant indices as well as standard demographic data.

\section{Methodological Considerations}

Randomisation: In a conventional RCT, randomisation reduces imbalances in demographic characteristics between the treatment groups (i.e. aims to reduce confounding). In an N-of-1 trial, however, randomisation is used to allocate the cycle of test treatment and comparator; it therefore (1) reduces systematic influences/periodicity over time (i.e. to achieve balance regarding the treatment/comparator, and perhaps lifestyle factors), and (2) helps maintain blinding to the different interventions. Thus, to minimise systematic error, the treatment under study ('A') and the comparator (' $B$ ') should be repeated in randomised order (e.g. cycles ABAB, ABBA, ABABBA, and ABBABAAB, etc.). 6,9,13,14 Trials with more than two treatments are also possible, e.g. with a treatment under study ('A'), an active control ('B'), and placebo or no treatment (' $C$ '). If, for example, each treatment is given in three cycles, a treatment sequence could be BCAABCCBA.

Carryover effect and washout period: A washout interval in the N-of- 1 design is important whenever a continuing effect of one treatment might influence outcome of a subsequent treatment period. ${ }^{6,8,34}$ Carryover effects of benefits or harms result from an insufficient washout period and may reduce differences observed between treatment and comparator. A possible disadvantage of a washout period is that the patient might spend some time without active treatment, which could be ethically unacceptable (see also Ethical considerations, below). ${ }^{35}$ If, for any reason, a washout period cannot be utilised, the use of 'analytical washout' ${ }^{34,35}$ can instead be considered; however, this approach, which aims to eliminate or down-weight observations taken at the beginning of a new treatment period, might reduce the statistical power of the study to detect a difference. ${ }^{35}$

For practical purposes, because the treatment response can differ from patient to patient, the treatment periods should be long enough to accommodate patients with a longer-than-average treatment response; as a consequence, outcome measurements should be collected with appropriate frequency.

Blinding: Blinding aims to keep patients and/or investigators and/or outcome assessors unaware of the assigned treatment cycle and therefore uninfluenced by knowledge of the intervention. $6,8,13,14,35$ As in any trial, blinding reduces several types of bias, e.g. performance bias, ascertainment bias, detection bias. Using an approach that is either doubleblinded (participants and investigators are blinded) or tripleblinded (the persons who analyse the study data are additionally blinded) is highly recommended. ${ }^{14}$

A common method used for blinding, if necessary, is to match drug and placebo by over-encapsulation of the pills or tablets under investigation. ${ }^{14}$ Participant blinding may not be possible in a comparative effectiveness $\mathrm{N}$-of- 1 study when the trial agent and comparator are readily distinguishable. In some cases, a solution to this problem may be the 'doubledummy' method, where a placebo for each agent or treatment is used, and the patient takes both (one active and one placebo product) in each cycle. ${ }^{14}$ If it is impossible to blind the patient and the physician, it may still be possible to blind the person who assesses the outcome(s).

Analysing data: There are different approaches to analysing the data from an $\mathrm{N}$-of- 1 trial. A simple and intuitive way is to plot the outcomes over time for each cycle and treatment and visually to inspect the results ${ }^{7-9}$ (- Fig. 1). This approach, however, is vulnerable to observer and expectation bias. Simple descriptive statistics, such as mean and standard deviation, can also be applied to the measured outcome data. ${ }^{35}$ In general, a method must be used that takes 


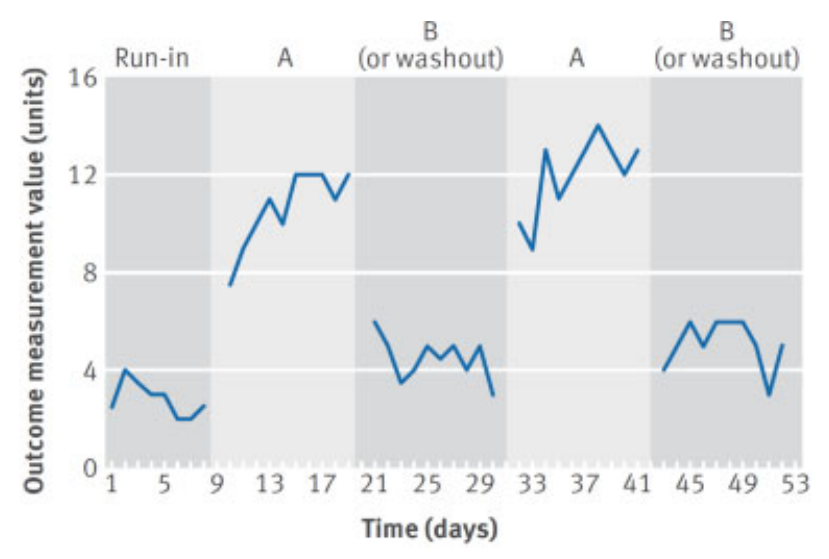

Fig. 1 Suggested visual representation of data from an N-of-1 trial. (Adapted from Vohra et al. ${ }^{9}$ )

the dependency and serial correlation (or 'autocorrelation') of the data into account, with data collected at closer timepoints showing a stronger correlation than data from more distant time-points. Depending on the study aim and trial design, one recommendation is to use a statistical approach such as non-parametric (e.g. sign test), parametric (e.g. paired $t$-test), Bayesian methods, or individual participant data(IPD) meta-analysis. ${ }^{35}$ As in the conventional crossover designs, generalised linear mixed-effects models (GLMMs) can usually be applied, either with continuous or with categorical outcomes, and account for the longitudinal structure of the data. In addition, since the $\mathrm{N}$-of- 1 trial resembles a time series, models that explicitly take the autocorrelation into account can be used: ${ }^{35}$ such a time-series model accommodates the dependency of the repeatedly measured values within a single subject.

Results: One major advantage of the N-of- 1 trial compared with conventional randomised trial designs is that at the end of the N-of- 1 study, the data can be unblinded and the results can be presented to the participant. In conventional RCTs, patients have to wait until all participants have finished the trial and the treatment allocation is unblinded.

Levels of data synthesis: The single-individual multi-cycle trial provides the first level of data synthesis for studies of this nature (-Table $\mathbf{1}$ ). Its data can be considered as corresponding to those of an idealised conventional multi-parti-

Table 1 Levels of synthesis for multi-cycle N-of-1 trials

\begin{tabular}{|l|l|}
\hline $\begin{array}{l}\text { Level of } \\
\text { synthesis }\end{array}$ & Study design \\
\hline 1 & One N-of-1 trial \\
\hline 2 & One series of N-of-1 trials \\
\hline 3 & More than one series of N-of-1 trials \\
\hline 4 & $\begin{array}{l}\text { More than one series of N-of-1 trials, together } \\
\text { with one or more conventional RCTs }\end{array}$ \\
\hline
\end{tabular}

Abbreviation: RCTs, randomised controlled trials. cipant RCT: ${ }^{36}$ for example, if an $\mathrm{N}$-of- 1 trial comprises three treatment/comparator cycles, it could be regarded like an RCT consisting of three participants who each have a perfectly matched control. ${ }^{36}$ As stated above, the raw outcome data for such an N-of-1 trial comprise the three pairs of measurements (treatment and comparator) which, most straightforwardly, can be aggregated per patient using simple statistics (mean, standard deviation); more complex statistical modelling, reflecting the autocorrelated nature of the data, can also be employed. ${ }^{35}$

Although an $\mathrm{N}$-of- 1 trial is performed to investigate whether a treatment works in a single individual, the aggregated data from several similar N-of- 1 trials can be pooled ${ }^{36-39}$ and analysed (- Table 1: level 2). Again, the most straightforward approach is to use simple statistics, while meta-analytic methods could also be used. If there were a series of individual patients participating in the same overall study-each as a multi-cycle N-of- 1 trial-it could be regarded as a cluster RCT in conventional terms. ${ }^{36}$

There are several advantages of aggregated $\mathrm{N}$-of- 1 studies compared with conventional RCTs: smaller sample size; arms of the treatment and comparator groups are perfectly matched; usefulness of data when participants withdraw prematurely but have finished a completed cycle; the individualised nature of the data. ${ }^{36}$ The disadvantages of aggregating N-of- 1 trial data compared with conventional RCTs include the lesser likelihood of the trial sample being representative of the wider relevant population and the difficulty of detecting low-prevalence side-effects. ${ }^{36}$

Systematic review and meta-analysis: The systematic review of $\mathrm{N}$-of- 1 trials aims to evaluate the quality and findings of $\mathrm{N}-\mathrm{of}-1$ trials, with analysis of data from several individual trials and/or series of trials (-Table 1: levels $1-3$ ). Data synthesis may also comprise the results from N-of- 1 trials combined with those from conventional RCTs (-Table 1: level 4$)^{32}$

Other considerations: Further practical considerations for conducting an N-of- 1 trial concern data collection and quality control, ${ }^{40}$ assessing and reporting of adverse events ${ }^{41}$ and cost-effectiveness analysis. ${ }^{42}$

\section{Ethical Considerations}

Guyatt et $\mathrm{al}^{8}$ have published ethics requirements for the implementation of $\mathrm{N}-\mathrm{of}-1$ trials, both in usual clinical care and in a research context. They mirror requirements for conventional RCTs. For a primarily research-oriented study in humans, the relevant Human Research Ethics Committees and Institutional Review Boards have to be included; ${ }^{43,44}$ the ICH Good Clinical Practice guidelines should also be fulfilled. ${ }^{45}$ If an $\mathrm{N}$-of- 1 trial is applied exclusively from a practical approach to improve the individual clinical care, ethics requirements may not necessarily apply.

A key requirement for an $\mathrm{N}$-of-1 study is therefore to differentiate the extent to which it is clinical care or a research project. To answer this question, Punja et al ${ }^{43}$ proposed five different overarching purposes of N-of-1 trials: two of those focus principally on clinical care, while three focus on research. Because the distinction between clinical 
care and research is not always obvious, some ostensibly clinical projects may also fall within Ethics Committee jurisdiction.

\section{Limitations}

$\mathrm{N}$-of- 1 trials are useful in a narrow range of medical situations (chronic stable conditions, quick onset interventions, etc.) and not suitable for rapidly progressive conditions, slow therapeutic onset, long-lasting carryover effects, or complex dosing or titration regimens. As highlighted above, N-of-1 trials cannot assess the effects of interventions on a so-called hard endpoint such as mortality, stroke, or heart failure. When performed by a single practicing physician without scientific or administrative support, they might be too timeconsuming and laborious to be included into daily practice routines: randomisation, blinding and possibly the preparation of matching placebos could be a high hurdle to overcome. If, at the end of the trial, both treatments seem to be equally effective, it is difficult to judge whether they are really equal in efficacy, or if the duration of the treatment periods was too short, the number of cycles was too few, the power was not sufficient, or if there was carryover of treatment effect.

\section{N-of-1 Trials in Complementary and Alternative Medicine}

The individualised patient care that is characteristic of CAM may be accommodated in $\mathrm{N}$-of- 1 study design if the patient and the specific therapeutic intervention are selected with the above needs of the method prominently in mind. In the mid-1990s, Gaus and Högel recommended N-of- 1 trials to investigate 'unconventional therapies' such as phytotherapy, acupuncture, and homeopathy. ${ }^{46}$ During the past 10 years, an increasing number of general articles on the implementation of $\mathrm{N}$-of- 1 trials in CAM has been published. ${ }^{47-50}$ Johnston and Mills stated: 'The N-of- 1 trial may have great clinical worth in the evaluation of CAM therapies through bridging the gap between research and clinical practice, allowing for an individualized approach, and incorporating patient values'. ${ }^{48}$ Patient values can be included, for example, by enabling their choice of intervention from feasible options. ${ }^{48}$

Johnston and Mills also suggested the following opportunities in evaluating CAM therapies by the $\mathrm{N}-\mathrm{of}-1$ trial approach: (1) due to its rigorous design, to reduce the risk of drawing invalid conclusions about clinical effectiveness; (2) to help identify individual responders while reducing the treatment times for non-responders; (3) to clarify optimal formulations of a CAM product in individual patients; (4) to evaluate different dosing regimens of a given CAM product to determine the balance between its effectiveness and its potential side-effects; (5) as a tool to investigate the placebo effect. ${ }^{48}$ For the latter, the authors explain that through such patient-centred trials, the placebo effect could be better examined and understood, for example by using a treatment period, a placebo period and a non-treatment period, and by investigating these in a double-blinded approach.
The same authors noted that, despite the potential usefulness of the N-of- 1 trial, it had not yet been incorporated widely into CAM research. ${ }^{48}$ For 'constitutional' prescribing in long-term or intractable illness, a situation that is not uncommon in individualised homeopathy, the N-of- 1 study design might be difficult to implement. ${ }^{48}$ Johnston and Mills cited another constraint as the contemporary absence of practical guidelines for $\mathrm{N}$-of- 1 trials, and recommended applying the Nahin and Straus approach to the use of population-based RCTs in CAM. ${ }^{51}$ As a further problem, the authors mentioned the expense of $\mathrm{N}$-of- 1 trials in the context of CAM. ${ }^{48}$ For example, the average cost of preparing placebos and medication can be relatively high ${ }^{48}$-though not for homeopathy, since placebo globules are very cheap. The authors concluded that the use of N-of- 1 trials can make 'an important contribution to CAM, particularly in the context of solving difficult clinical scenarios, treating rare, resistant, or heterogeneous illnesses, and evaluating the usefulness of CAM therapies'. ${ }^{48}$ Recently, Goldenberg and Wenner proposed investigating individual responders, who had been identified in a 'parent' RCT, in a follow-up 'mixedmethodology add-on N-of- 1 trial'. 50

Sung and Feldman described the possibilities of using $\mathrm{N}$-of-1 trials for evaluating CAMs in individual paediatric cancer patients. In addition, they recognised that 'the N-of-1 trial allows parents and children to voice preferences about treatment options and allows them to directly participate in balancing adverse events and therapeutic benefits'. ${ }^{49}$ Supportive-care interventions, such as acute therapy to reduce side effects of chemotherapy, or treatments to deal with relatively stable late effects of cancer, such as post-therapy fatigue, might be suited to this trial design. ${ }^{49}$

The N-of-1 trial design was used to evaluate the effect of Valerian compared with placebo for chronic insomnia in the general practice setting. ${ }^{52}$ The response to Valerian was only poor or modest for each of 24 participants' total sleep time and wakefulness at night, but their energy levels did increase more noticeably. The authors attributed the modest effects to the small dose of Valerian investigated. ${ }^{52}$

Several articles have reported the use of N-of- 1 trials in Traditional Chinese Medicine (TCM) ${ }^{53-57}$ and in Japanesestyle acupuncture. ${ }^{58,59}$ The TCM studies variously addressed the difficulties of optimising treatment and washout periods, ${ }^{55,56}$ autocorrelation, repeated-measures analysis, and acute exacerbation of symptoms. ${ }^{56}$ In a 47 -patient N-of- 1 series, other authors were able to distinguish between responders, possible responders and non-responders to treatment. $^{55}$ In acupuncture, an N-of- 1 trial was proposed as a useful research design for evaluating the long-term efficacy of treatment in individuals: ${ }^{58}$ this proposition was based on investigation in a patient with chronic bronchial asthma who had an acupuncture session once per week for 10 weeks, followed by 9 weeks of no treatment, 12 weeks of treatment, and a final period of no treatment. Symptoms were reduced during each treatment period but returned during the no-treatment cycles. Kawakita et $\mathrm{al}^{59}$ performed $\mathrm{N}$-of-1 trials of acupuncture with moxibustion on two elderly people suffering from common cold, allocating 
treatment and control (conventional treatment only) periods in random order ( 8 weeks treatment, 8 weeks control): no statistically significant differences were observed. Jackson et $\mathrm{al}^{53}$ explored the benefits of acupuncture in each of six patients with tinnitus in a series of controlled N-of- 1 trials. The patients received a course of 10 acupuncture treatments over a 2-week period and recorded, on a daily basis, the symptoms loudness, pitch, waking hours affected, and quality of sleep. Most patients experienced benefits in selfreported symptoms.

Li et $\mathrm{al}^{57}$ reviewed the contemporary status of the use of $\mathrm{N}$-of- 1 trials in China. Eleven relevant studies were identified: three N-of- 1 trials and eight reviews of $\mathrm{N}-\mathrm{of}-1$ trials. The authors concluded: 'While N-of- 1 trials may offer a good tool to individualize clinical care and enrich TCM clinical research, they have not been widely used to date'. To support the development of this method, the authors highlight three points: 'First, the Chinese government should endorse and sponsor N-of-1 studies; second, researchers and physicians should be systematically trained in the method; third, thorough considerations [about N-of-1] trials allow better research and focus on the patients' needs. ${ }^{57}$

\section{N-of-1 Trials in Homeopathy}

Some scientists have highly recommended the use of N-of-1 trials in homeopathy. ${ }^{59-61}$ We have been unable, however, to identify any N-of- 1 trials in homeopathy in the peer-reviewed literature to date. In principle, as for CAM, the frequently individualised nature of the homeopathic intervention lends itself conceptually to the N-of- 1 trial approach, though the same caveats about durations of illness, treatment and washout will certainly apply. In targeting potential applications of the N-of- 1 method in homeopathy, therefore, the clinical requirement is the same as for the general case: ${ }^{6,8,9}$ a chronic stable condition for which a given homeopathic intervention is recognised (from clinical experience and/or prior controlled research) to have quick onset and termination of effect, and with negligible carryover.

In our opinion, there are three main targets for the immediate investigation of homeopathy with $\mathrm{N}$-of- 1 trial designs: (1) to optimise clinical care in an individual patient by comparing the effects of homeopathic treatment with other treatments (conventional or other CAM method); (2) to investigate whether the outcomes of treatment using homeopathy differ from those of placebo in a given patient; (3) to aggregate data from a series of several similarly designed N-of-1 trials to draw conclusions about a given intervention or group of similar patients. Ultimately, we foresee a fourth key target: to conduct meta-analysis on the results from several series of $\mathrm{N}$-of- 1 trials (and potentially together with results from relevant conventional RCTs).

We have emphasised that the $\mathrm{N}$-of- 1 trial design may be especially useful in homeopathy because of the individualised nature of the homeopathic intervention. We acknowledge, however, that such prescribing often addresses deeply seated, constitutional or complex disorders whose treatment strategy to achieve longer-term improvement is potentially less readily amenable to the $\mathrm{N}-\mathrm{of}-1$ trial method; ${ }^{48}$ some studies in CAM have nevertheless shown that it is feasible. ${ }^{53,58}$ Homeopathic practitioners prescribe high-potency medicines in some such situations of constitutional prescribing. ${ }^{62}$ In considering applying the N-of- 1 method in such cases, the use of $\mathrm{Q} / \mathrm{LM}$ or low potencies (such as C6) may be a logical approach: these are prescribed for higher frequency use (e.g. daily) and are believed to result in more rapid-onset or shorter-lasting clinical effects than high potencies (such as C30 or C200). ${ }^{62}$ Q-potencies are especially prescribed for higher-frequency intake. ${ }^{63}$

Using the approach of clinical homeopathy, homeopathic medicines are also often prescribed for a patient by less indepth or individualising approaches, as so-called established therapeutic indications for standard clinical conditions or symptoms, using products such as Galphimia glauca for acute pollinosis $^{64}$ or using complex remedies for more general disease conditions. As for conventional treatments, the N-of1 design may confidently be used in homeopathy using such an approach.

The general methodological considerations-e.g. randomisation, blinding, aggregating and analysing data, research ethics, as well as the limitations of the method-that we have expressed earlier in this article are important also for the application of the N-of-1 trial design in homeopathy. The new CENT guidelines, ${ }^{9,19-21}$ which aim to increase highquality conduct and reporting of $\mathrm{N}$-of- 1 trials, seem to offer a timely basis for such research contribution in homeopathy.

In conventional medicine, conditions frequently studied by $\mathrm{N}$-of-1 design include dyspepsia, attention-deficit hyperactivity disorder (ADHD), osteoarthritis and insomnia, ${ }^{23}$ the latter three of which have been investigated as well by conventionally designed RCTs in homeopathy. ${ }^{65-67} \mathrm{~N}$-of-1 research may also be adaptable to study homeopathy in episodic, periodic, or seasonal conditions such as migraine, pre-menstrual syndrome (PMS) or allergic rhinitis, each of which possesses a tangible RCT literature in homeopathy. ${ }^{64,68-71}$ Other promising candidates for the N-of-1 approach in homeopathy are chronic pain associated with fibromyalgia, for which there is already some high-quality RCT research evidence ${ }^{72}$ and, depending on the stability or regularity of the complaints, depression, whose non-conclusive RCT findings in homeopathy to date seem partly due to poor recruitment of subjects. ${ }^{73,74}$ Indeed, an editorial connected with one of the unproductive depression RCTs ${ }^{73}$ commented, 'homeopathy research may advance best by retaining a patient-centred emphasis on the individual, drawn from its own clinical practice'. ${ }^{75}$ Eligibility criteria for individual trials can, where appropriate, include patients with co-morbidity.

In considering the specifics of $\mathrm{N}$-of- 1 trial design in a given individual, we recognise that the duration of a homeopathic medicine effect and the duration of the comparator effect might differ. Also, for episodic, periodic, or seasonal medical conditions, the observation periods between interventions need to be sufficiently long to ensure that the likely frequency of episodes is taken into account: the consequent $\mathrm{N}$-of- 1 trial could possibly be of longer than average duration 
to make sure that any homeopathic effect can be verified. For longer trials, however, it may be difficult to recruit and/or to retain patients. Although there is an increased risk of participant drop-out in longer-duration trials, an advantage of $\mathrm{N}$-of-1 trial design nevertheless is that patients are usually highly motivated due to the fact that the trial is being conducted for them as individuals. They may therefore be more committed to data collection and so be less likely to miss visits or fail to complete forms conscientiously. ${ }^{19}$

Finally, we provide an example of an N-of-1 design that might be suitable for a patient suffering from allergic rhinitis and who is interested in alternative medication. A simple ' $A B$ ' design may be applied to test which of the two therapies works better for that person: ' $A$ ' is a homeopathic medication at low potency; ' $\mathrm{B}$ ' is an antihistamine. There are intermediate washout periods without any treatment intervention. Existing medications, or 'rescue' medication, are allowed and their impact assessed. Consecutive cycles of the phases ' $A$ ' and ' $\mathrm{B}$ ' are administered in random sequence. For example, the duration of the trial could be 14 weeks, comprising a 2-week lead-in period, followed by 12 weeks made up of: 1 -week randomly selected intervention ' $A$ ' or ' $B$ ', 1 -week washout period, 1 -week randomly selected intervention ' $A$ ' or ' $B$ ', etc., so that at the end three cycles of ' $A$ ' and three cycles of 'B' are randomly implemented (e.g. BAABBA or ABBABA). Patient blinding can be achieved using the 'double-dummy' strategy. At specific points-for example, at the beginning, in the middle and at the end of each period 'A', washout and 'B' -the patient is asked to rate treatment success with simple questionnaires or outcome scales regarding allergic rhinitis symptoms. At the end of the trial, the results are evaluated, and the patient and the doctor are in a position to assess which (if either) therapeutic strategy is superior. In an extended trial design, comprising a series of several individual patients with similar symptoms, and if the above antihistamine was replaced by a placebo, it may be possible to derive more generalisable insights about treatment efficacy through suitable aggregation of data. Another option for an extended trial design would be to apply three different interventions in random sequence: homeopathic medication ' $A$ ', antihistamine ' $B$ ' and placebo (or no therapy) ' $C$ ', in random order, with suitable intermediate washout periods.

\section{Conclusion}

The application of the N-of-1 clinical trial design in homeopathy has important opportunities as well as limitations. The value of the N-of- 1 trial in research is that it is based on single-case investigative design but applies the principles of the conventional crossover RCT. Thus, the internal validity is high, especially when the trial conducted is randomised, double-blinded and placebo-controlled. The key principle of homeopathy as an individualised approach to patient care may be more naturally accommodated in an $\mathrm{N}-\mathrm{of}-1$ trial than in a conventional RCT; however, care must be taken to ensure that a therapeutic response and washout can reasonably be anticipated from the intervention within the study's timeframe. Less in-depth approaches to prescribing, such as clinical homeopathy, are also amenable to investigation using the N-of- 1 method. In all cases, it is the individuality of a given patient's clinical response that is the key motive for investigation. The data from several similar N-of- 1 trials can be aggregated, offering the opportunity for cautious generalisation of findings. The N-of- 1 approach should be actively explored in homeopathy as a means to optimise individualised healthcare or to investigate effectiveness compared with placebo in individual subjects.

\section{Conflict of Interest \\ None declared.}

\section{Authors' Contributions}

S.U.Z. and R.T.M. co-developed the original concept. S.U.Z. devised the manuscript and led its writing. Each author has provided edited content and has approved the final manuscript.

\section{Funding}

The study was supported by grants from the Swiss Homeopathy Association and the PanMedion Foundation, Switzerland.

\section{References}

1 Kleijnen J, Knipschild P, ter Riet G. Clinical trials of homoeopathy. BMJ 1991;302:316-323

2 Linde K, Clausius N, Ramirez G, et al. Are the clinical effects of homeopathy placebo effects? A meta-analysis of placebo-controlled trials. Lancet 1997;350:834-843

3 Linde K, Scholz M, Ramirez G, Clausius N, Melchart D, Jonas WB. Impact of study quality on outcome in placebo-controlled trials of homeopathy. J Clin Epidemiol 1999;52:631-636

4 Cucherat M, Haugh MC, Gooch M, Boissel JP; Homeopathic Medicines Research Advisory Group. Evidence of clinical efficacy of homeopathy. A meta-analysis of clinical trials. Eur J Clin Pharmacol 2000;56:27-33

5 Shang A, Huwiler-Müntener K, Nartey L, et al. Are the clinical effects of homoeopathy placebo effects? Comparative study of placebo-controlled trials of homoeopathy and allopathy. Lancet 2005;366:726-732

6 Kravitz RL, Duan N, Vohra S, Li J; the DEcIDE Methods Center N-of1 Guidance Panel. Introduction to N-of-1 trials: indications and barriers. In: Kravitz RL, Duan N, eds. Design and Implementation of N-of-1 Trials: A User's Guide. AHRQ Publication No. 13(14)EHC122-EF. Rockville, MD: Agency for Healthcare Research and Quality; 2014:1-12

7 Guyatt G, Zhang Y, Jaeschke R, McGinn T. N-of-1 randomized clinical trials. In: Guyatt G, Rennie D, Meade MO, Cook DJ, eds. User's Guide to the Medical Literature: A Manual for EvidenceBased Clinical Practice. 3rd ed. Chicago: McGraw-Hill Professional; 2015:151-161

8 Guyatt G, Sackett D, Adachi J, et al. A clinician's guide for conducting randomized trials in individual patients. CMAJ 1988;139:497-503

9 Vohra S, Shamseer L, Sampson M, et al; CENT Group. CONSORT extension for reporting N-of- 1 trials (CENT) 2015 statement. BM] 2015;350:h1738

10 Nikles J. What are N-of-1 trials? In: Nikles J, Mitchell G, eds. The Essential Guide to N-of-1 Trials in Health. Heidelberg: Springer; 2015:9-18

11 Tate RL, McDonald S, Perdices M, Togher L, Schultz R, Savage S. Rating the methodological quality of single-subject designs and 
n-of-1 trials: introducing the Single-Case Experimental Design (SCED) Scale. Neuropsychol Rehabil 2008;18:385-401

12 Tate RL, Perdices M, Rosenkoetter U, et al. Revision of a method quality rating scale for single-case experimental designs and n-of1 trials: the 15 -item risk of bias in N-of-1 Trials (RoBiNT) Scale. Neuropsychol Rehabil 2013;23:619-638

13 Carriere KC, Li Y, Mitchell G, Senior H. Methodological considerations of N-of-1 trials. In: Nikles J, Mitchell G, eds. The Essential Guide to N-of-1 Trials in Health. Heidelberg: Springer; 2015: 67-80

14 Senior H. Randomization, allocation concealment, and blinding. In: Nikles J, Mitchell G, eds. The Essential Guide to N-of-1 Trials in Health. Heidelberg: Springer; 2015:81-92

15 Guyatt G, Sackett D, Taylor DW, Chong J, Roberts R, Pugsley S. Determining optimal therapy-randomized trials in individual patients. N Engl J Med 1986;314:889-892

16 Larson EB. N-of-1 clinical trials. A technique for improving medical therapeutics. West J Med 1990;152:52-56

17 Kravitz RL, Duan N, Niedzinski EJ, Hay MC, Subramanian SK, Weisner TS. What ever happened to $\mathrm{N}$-of-1 trials? Insiders' perspectives and a look to the future. Milbank Q 2008; 86:533-555

18 Lillie EO, Patay B, Diamant J, Issell B, Topol EJ, Schork NJ. The n-of-1 clinical trial: the ultimate strategy for individualizing medicine? Per Med 2011;8:161-173

19 Kravitz RL, Duan N, eds. Design and Implementation of N-of-1 Trials: A User's Guide. AHRQ Publication No. 13(14)-EHC122-EF. Rockville, MD: Agency for Healthcare Research and Quality; 2014

20 Nikles J, Mitchell G, eds. The Essential Guide to N-of-1 Trials in Health. Heidelberg: Springer; 2015

21 Shamseer L, Sampson M, Bukutu C, et al; CENT Group. CONSORT extension for reporting $\mathrm{N}$-of-1 trials (CENT) 2015: explanation and elaboration. BMJ 2015;350:h1793

22 Gabler NB, Duan N, Vohra S, Kravitz RL. N-of- 1 trials in the medical literature: a systematic review. Med Care 2011;49:761-768

23 Punja S, Bukutu C, Shamseer L, et al. Systematic review of the methods, statistical analysis and meta-analysis of $\mathrm{N}-\mathrm{of}-1$ trials. In: Punja S, ed. N-of-1 Methods and their Contribution to Systematic Reviews and Meta-Analyses [thesis]. University of Alberta; 2014:13-47

24 Shaffer JA, Falzon L, Cheung K, Davidson KW. N-of-1 randomized trials for psychological and health behavior outcomes: a systematic review protocol. Syst Rev 2015;4:87

25 Li J, Gao W, Punja S, et al. Reporting quality of N-of-1 trials published between 1985 and 2013: a systematic review. J Clin Epidemiol 2016;76:57-64

26 Nikles J. Where are N-of- 1 trials headed? In: Nikles J, Mitchell G, eds. The Essential Guide to N-of-1 Trials in Health. Heidelberg: Springer; 2015:233-242

27 Schwartz D, Lellouch J. Explanatory and pragmatic attitudes in therapeutical trials. J Clin Epidemiol 2009;62:499-505

28 International Conference on Harmonisation of Technical Requirements for Registration of Pharmaceuticals for Human Use. Choice of Control Group in Clinical Trials 2000. Available at: http://www.ich. org/fileadmin/Public_Web_Site/ICH_Products/Guidelines/Efficacy/E10/Step4/E10_Guideline.pdf. Accessed December 3, 2016

29 International Conference on Harmonisation of Technical Requirements for Registration of Pharmaceuticals for Human Use. Statistical Principles for Clinical Trials 1998. Available at: http://www.ich. org/fileadmin/Public_Web_Site/ICH_Products/Guidelines/Efficacy/E9/Step4/E9_Guideline.pdf. Accessed December 3, 2016

30 Schulz KF, Altman DG, Moher D; CONSORT Group. CONSORT 2010 statement: updated guidelines for reporting parallel group randomised trials. Int J Surg 2011;9:672-677

31 Guyatt G, Jaeschke R, Wilson MC, Montori VM, Richardson WS. What is evidence-based medicine? In: Guyatt G, Rennie D, Meade MO, Cook DJ, eds. User's Guide to the Medical Literature: A
Manual for Evidence-Based Clinical Practice. 3rd ed. Chicago: McGraw-Hill Professional; 2015:7-14

32 Punja S, Schmid CH, Hartling L, Urichuk L, Nikles CJ, Vohra S. Amphetamine and methylphenidate for pediatric ADHD: a combined meta-analysis of N-of-1 trial data with RCT data. In: Punja $\mathrm{S}$, ed. N-of-1 Methods and Their Contribution to Systematic Reviews and Meta-Analyses [thesis]. University of Alberta; 2014:197-212

33 Punja S. N-of-1 Methods and Their Contribution to Systematic Reviews and Meta-Analyses [thesis]. University of Alberta; 2014

34 Duan N, Kravitz RL, Schmid CH. Single-patient (n-of-1) trials: a pragmatic clinical decision methodology for patient-centered comparative effectiveness research. J Clin Epidemiol 2013;66: S21-S28

35 Schmid CH, Duan N. The DEcIDE Methods Center N-of-1 Guidance Panel. Statistical design and analytic considerations for N-of-1 trials. In: Kravitz RL, Duan N, eds. Design and Implementation of N-of-1 Trials: A User's Guide. AHRQ Publication No. 13(14)EHC122-EF. Rockville, MD: Agency for Healthcare Research and Quality; 2014:33-54

36 Mitchell G. Aggregated N-of-1 trials. In: Nikles J, Mitchell G, eds. The Essential Guide to N-of-1 Trials in Health. Heidelberg: Springer; 2015:57-66

37 Zucker DR, Schmid CH, McIntosh MW, D'Agostino RB, Selker HP, Lau J. Combining single patient ( $\mathrm{N}-\mathrm{of}-1$ ) trials to estimate population treatment effects and to evaluate individual patient responses to treatment. J Clin Epidemiol 1997;50:401-410

38 Zucker DR, Ruthazer R, Schmid CH. Individual (N-of-1) trials can be combined to give population comparative treatment effect estimates: methodologic considerations. J Clin Epidemiol 2010; 63:1312-1323

39 Nikles J, Mitchell GK, Schluter P, et al. Aggregating single patient (n-of-1) trials in populations where recruitment and retention was difficult: the case of palliative care. J Clin Epidemiol 2011; 64:471-480

40 Senior H. Data collection and quality control. In: Nikles J, Mitchell G, eds. The Essential Guide to N-of-1 Trials in Health. Heidelberg: Springer; 2015:93-104

41 Senior H. Assessing and reporting adverse events. In: Nikles J, Mitchell G, eds. The Essential Guide to N-of-1 Trials in Health. Heidelberg: Springer; 2015:115-124

42 Whitty JA, Byrnes JM, Scuffham PA. The economics of N-of-1 trials. In: Nikles J, Mitchell G, eds. The Essential Guide to N-of-1 Trials in Health. Heidelberg: Springer; 2015:155-174

43 Punja S, Vohra S, Eslick I, Duan N; the DEcIDE Methods Center Nof-1 Guidance Panel. An ethical framework for N-of-1 trials: Clinical care, quality improvement, or human subjects research? In: Kravitz RL, Duan N, eds. Design and Implementation of N-of-1 Trials: A User's Guide. AHRQ Publication No. 13(14)-EHC122-EF. Rockville, MD: Agency for Healthcare Research and Quality; 2014: 13-22

44 Crowden A, Guyatt G, Stepanov N, Vohra S. Research ethics and N-of-1 trials. In: Nikles J, Mitchell G, eds. The Essential Guide to N-of-1 Trials in Health. Heidelberg: Springer; 2015:125-134

45 International Conference on Harmonisation of Technical Requirements for Registration of Pharmaceuticals for Human Use. Guideline for Good Clinical Practice 1996. Available at: http://www.ich. org/products/guidelines/efficacy/efficacy-single/article/goodclinical-practice.html. Accessed July 12, 2016

46 Gaus W, Högel J. Studies on the efficacy of unconventional therapies. Problems and designs. Arzneimittelforschung 1995;45:88-92

47 Hart A, Sutton CJ. n-of- 1 trials and their combination: suitable approaches for CAM research? Complement Ther Med 2003; 11:213-214

48 Johnston BC, Mills E. N-of-1 randomized controlled trials: an opportunity for complementary and alternative medicine evaluation. J Altern Complement Med 2004;10:979-984 
49 Sung L, Feldman BM. N-of-1 trials: innovative methods to evaluate complementary and alternative medicines in pediatric cancer. J Pediatr Hematol Oncol 2006;28:263-266

50 Goldenberg JZ, Wenner CA. A novel N of 1 trial design and proposed utility in complementary and alternative medicine research. J Evid Based Complementary Altern Med 2012;17:126-130

51 Nahin RL, Straus SE. Research into complementary and alternative medicine: problems and potential. BMJ 2001;322:161-164

52 Coxeter PD, Schluter PJ, Eastwood HL, Nikles CJ, Glasziou PP. Valerian does not appear to reduce symptoms for patients with chronic insomnia in general practice using a series of randomised n-of-1 trials. Complement Ther Med 2003;11:215222

53 Jackson A, MacPherson H, Hahn S. Acupuncture for tinnitus: a series of $\operatorname{six} n=1$ controlled trials. Complement Ther Med 2006; 14:39-46

54 Lee S, Lim N, Choi SM, Kim S. Validation study of Kim's sham needle by measuring facial temperature: an $\mathrm{N}$-of- 1 randomized double-blind placebo-controlled clinical trial. Evid Based Complement Alternat Med 2012. doi: 10.1155/2012/507937

55 Yuhong H, Qian L, Yu L, et al. An N-of-1 trial service in clinical practice: testing the effectiveness of Liuwei Dihuang decoction for kidney-Yin deficiency syndrome. Evid Based Complement Alternat Med 2013. doi: 10.1155/2013/827915

56 Huang H, Yang P, Xue J, et al. Evaluating the individualized treatment of traditional Chinese medicine: a pilot study of N-of- 1 trials. Evid Based Complement Alternat Med 2014. doi: 10.1155/2014/148730

57 Li J, Tian J, Ma B, Yang K. N-of-1 trials in China. Complement Ther Med 2013;21:190-194

58 Kawakita K, Suzuki M, Namura K, Tanzawa S. A proposal for a simple and useful research design for evaluating the efficacy of acupuncture: multiple, randomized n-of- 1 trials. Japanese Acupuncture and Moxibustion 2005;1:9-15

59 Kawakita K, Shichidou T, Inoue E, et al. Do Japanese style acupuncture and moxibustion reduce symptoms of the common cold? Evid Based Complement Alternat Med 2008;5:481-489

60 Witt C, Linde K. Clinical Research in Complementary and Integrative Medicine: A Practical Training Book. Munich: Urban \& Fischer Verlag/Elsevier GmbH; 2011

61 Teut M, Linde K. Scientific case research in complementary and alternative medicine-a review. Complement Ther Med 2013; 21:388-395
62 Dahler J. Potenzen und ihre k Dosierung. In: Teut M, Dahler J, Lucae C, et al, eds. Kursbuch Homöopathie. 2nd ed. München: Urban \& Fischer Verlag/Elsevier GmbH; 2016:135-148

63 Hahnemann S. Organon der Heilkunst. Originalgetreuer Nachdruck der sechsten Auflage von 1921. Kandern, Germany: Narayana-Verlag; 2011

64 Ludtke R, Wiesenauer M. A meta-analysis of the homeopathic treatment of pollinosis with Galphimia glauca. Forsch Komplementarmed 1996;3:230-236

65 Cooper KL, Relton C. Homeopathy for insomnia: a systematic review of research evidence. Sleep Med Rev 2010;14:329-337

66 Ernst E. Homeopathy for insomnia and sleep-related disorders: a systematic review of randomised controlled trials. Focus Altern Complement Ther 2011;16:195-199

67 Long L, Ernst E. Homeopathic remedies for the treatment of osteoarthritis: a systematic review. Br Homeopath J 2001;90:37-43

68 Taylor MA, Reilly D, Llewellyn-Jones RH, McSharry C, Aitchison TC. Randomised controlled trial of homoeopathy versus placebo in perennial allergic rhinitis with overview of four trial series. BMJ 2000;321:471-476

69 Ernst E. Homeopathic Galphimia glauca for hay fever: a systematic review of randomised clinical trials and a critique of a published meta-analysis. Focus Altern Complement Ther 2011; 16:200-203

70 Ernst E. Homeopathic prophylaxis of headaches and migraine? A systematic review. J Pain Symptom Manage 1999;18:353-357

71 Yakir M, Kreitler S, Brzezinski A, Vithoulkas G, Oberbaum M, Bentwich Z. Effects of homeopathic treatment in women with premenstrual syndrome: a pilot study. Br Homeopath J 2001; 90:148-153

72 Mathie RT, Lloyd SM, Legg LA, et al. Randomised placebo-controlled trials of individualised homeopathic treatment: systematic review and meta-analysis. Syst Rev 2014;3:142

73 Katz T, Fisher P, Katz A, Davidson J, Feder G. The feasibility of a randomised, placebo-controlled clinical trial of homeopathic treatment of depression in general practice. Homeopathy 2005; 94:145-152

74 Adler UC, Krüger S, Teut M, et al. Homeopathy for depression: a randomized, partially double-blind, placebo-controlled, fourarmed study (DEP-HOM). PLoS One 2013;8:e74537

75 Bell IR. Depression research in homeopathy: hopeless or hopeful? Homeopathy 2005;94:141-144 